\title{
A Hospital-Based Insight into the Antinuclear Antibody Patterns in Autoimmune Disorders
}

\author{
Prishni Gupta ${ }^{1}$ Ritu Priya ${ }^{1} \quad$ Rachita Nanda ${ }^{1, \odot}$ Suprava Patel ${ }^{1} \quad$ Eli Mohapatra ${ }^{1}$ \\ ${ }^{1}$ Department of Biochemistry, All India Institute of Medical \\ Sciences, Raipur, Chhattisgarh, India \\ Address for correspondence Rachita Nanda, MBBS, MD, \\ Department of Biochemistry, Medical College, AlIMS Raipur, \\ Chhattisgarh, 492099, India (e-mail: dr.rachitananda@gmail.com).
}

\begin{abstract}
Keywords

- central India

- immunofluorescence assay

- nuclear
\end{abstract}

Background The incidence of autoimmune disorders has seen a rise in India in recent times. The symptoms and signs of these conditions are caused by a systemic autoimmune response, essentially characterized by the expression of the antinuclear antibodies (ANA). Presence of ANA in serum of patient could be the prime evidence of an autoimmune disorder.

Aim This study aimed to determine the antibody patterns and assess the clinical significance of ANA in patients of a teaching tertiary care hospital of central India.

Material and Methods This retrospective cross-sectional data analysis study retrieved 538 reports of individuals, who were prescribed the ANA test by indirect immunofluorescence assay over a period of 11 months, from the archives of the Department of Biochemistry. For continuous data, student $t$-test was used while Chisquare and Fisher exact was conducted for categorical data. A $p$ value less than 0.05 were taken as significant.

Results Out of the 538 patients investigated for ANA testing by indirect immunofluorescence assay, $33 \%$ were positive, among which $74 \%$ were female, and majority belonged to the young adult age group. The most common pattern identified was nuclear, subpattern nuclear speckled.

Conclusion A high-ANA pattern positivity could be related to a high-autoimmunity prevalence in this region, and also promotes its use as a tool of evidence of suspected autoimmune disorders.

\section{Introduction}

In general, when a patient presents with clinical manifestations associated with autoimmune condition, the first test advised is antinuclear antibody (ANA) ${ }^{1}$ that serve as the serological hallmarks of autoimmunity. ${ }^{2}$ The ANA attack self-proteins within cell nucleus structures, now encompassing nuclear envelope components, mitotic spindle apparatus, cytosol, cytoplasmic organelles, and cell membranes. ${ }^{3}$ Their presence in serum may indicate either a systemic autoimmune disease like systemic lupus erythematosus (SLE), scleroderma and polymyositis/ dermatomyositis, or an organ-specific condition like autoimmune thyroiditis and hepatitis. ${ }^{2}$ Identification of ANA patterns and their target antigen on the basis of variable cellular staining pattern can be correlated to specific autoimmune disease as part of diagnostic clinical immunology. ${ }^{2,4}$ Although a collection of tests are available for ANA detection, the indirect immunofluorescence (IIF)-ANA on HEp-2 cells remains the gold standard. ${ }^{5}$

The autoimmune disorders are responsible for considerable morbidity and mortality in Western countries, with prevalence of 3 to $5 \%$. However, the condition in Asian countries like India is still blurred because only a few studies on individual diseases have been undertaken. ${ }^{6}$ Thus, the present study aims to determine the ANA positivity, study the ANA patterns, and assess their clinical significance in patients afflicted with autoimmune disorders from central India. 


\section{Materials and Methods}

In this retrospective cross-sectional data analytic study, we retrieved and reviewed 538 ANA test reports, between January to November, 2018, from the archives of the Department of Biochemistry of a tertiary care center in Central India, irrespective of age and specialty departments.

IIF assay has been positioned as the gold standard for ANA testing by the American College of Rheumatology, with the advent of utilizing a cell-line substrate from human laryngeal carcinoma cells and Hep-2 cells, combined with a primate liver. In our center, ANA in serum was detected using the EUROIMMUN titer-plane technique. The kit comprised of Biochip slides embedded with HEp-20-10/liver (monkey) tissue sections. As per the manufacturer protocol, serum samples were diluted 1:100 with phosphate buffer saline (PBS)-Tween followed by tagging with fluorescein-labeled antihuman globulin. ANA binding to specific antigen leads to a fluorescent emission that was visualized under an inverted fluorescence microscope under $10 \times$ and $40 \times$ objectives. The fluorescent intensity of each sample was compared with both negative and positive control that were supplied in the kit. The grouping and classification of ANA patterns were as per the ICAP (International Congress on Antinuclear Antibody Patterns) nomenclature. The records that were analyzed were categorized based on demographic factors and clinical information available in the patient requisition forms.

\section{Data Analysis}

The data collected was analyzed in IBM SPSS 21. For continuous data, student $t$-test was used, while Chi-square and Fisher exact was done for categorical data. A $p$ value less than 0.05 were taken as significant.

\section{Results}

Out of the 538 ANA reports that were reviewed, 33\% (179) were positive for ANA. Although, the patients belonged from different disciplines of the hospital, general medicine that includes endocrinology contributed to maximum patient load ( - Table 1).

ANA positivity was maximum in the 30 to 39 age group patient population, mean age being $37 \pm 18$ years $(p<0.001)$ (-Table 2). Females were more affected than males in ratio $1: 2.8(p=0.03)$. All the age groups had females more positive than males, although the difference was not statistically significant (-Table 3).

The different patterns that were found in this study are depicted in - Table 4. The nuclear pattern was the most common (68.7\%), and amongst its subtypes, nuclear speckled pattern predominated the results (24\%), followed by nuclear homogenous (21.2\%); similarly, $18.9 \%$ patients had the cytoplasmic pattern, with $8.4 \%$ showing the cytoplasmic speckled pattern.

The patient population belonging to the 30 to 39 age group showed positivity for every pattern except nuclear envelope and mitotic intercellular bridge. The nuclear speckled pattern was seen in all age groups and so did the cytoplasmic speckled pattern but in fewer numbers, although with no patients in the 0 to 9 years age group. All the other subpatterns showed sporadic appearances in the different age groups (-Supplementary Table S1, online only).

Further, 162 patients were segregated based on available clinical data, symptoms and diagnosis. - Table 5 shows the disease spectra versus age group distribution numbers. Most patients were in the 30- to 39-years age group and maximum of them had an underlying skin disorder (acne vulgaris, pemphigus vulgaris, bulous pemphigoid), followed by patients with infections and inflammatory conditions. The next in majority were patients with various rheumatoid diseases with

Table 1 Distribution of total and positive cases across clinical disciplines

\begin{tabular}{|c|c|c|c|c|c|}
\hline Departments & OPD & IPD & Total (n) & Positive (n) & Positivity \% \\
\hline General medicine/endo & 175 & 60 & 235 & 74 & 41.34 \\
\hline Trauma/casualty & 7 & 39 & 46 & 18 & 10.06 \\
\hline Pediatrics & 35 & 17 & 52 & 15 & 8.38 \\
\hline Orthopaedics & 68 & 3 & 71 & 24 & 13.41 \\
\hline Dermatology & 43 & 9 & 52 & 21 & 11.73 \\
\hline Cardiology & 8 & 0 & 8 & 3 & 1.68 \\
\hline Neurology & 18 & 1 & 19 & 3 & 1.68 \\
\hline Pulmonary medicine & 21 & 2 & 23 & 11 & 6.15 \\
\hline ENT & 8 & 1 & 9 & 4 & 2.23 \\
\hline Ophthalmology & 11 & 1 & 12 & 3 & 1.68 \\
\hline OBG & 5 & 3 & 8 & 1 & 0.56 \\
\hline Psychiatry & 1 & 1 & 2 & 1 & 0.56 \\
\hline Surgery & 0 & 1 & 1 & 1 & 0.56 \\
\hline Total & 400 & 138 & 538 & $179(33 \%)$ & 100 \\
\hline
\end{tabular}


two age peaks, adolescent and young adult. A similar peaking was seen with the hematological conditions. While infections were more common in the adolescents, skin conditions were mostly seen in the early adult age group. Lupus had a homogenous distribution in all age groups till 70 years.

ANA positivity was observed in $54.5 \%$ patients afflicted with SLE or discoid lupus erythematosus (DLE), with a statistically significant bias toward nuclear homogenous pattern. A similar statistically significant distribution was seen in the rheumatoid disease group with a $38.9 \%$ positivity rate, and the skin conditions with a $47.8 \%$ positivity rate. The study did not find a positive ANA result in nephrotic syndrome, endocrine disorders, and Hansen's disease. The nuclear speckled pattern was seen in all conditions except in SLE and DLE, but the highest percentage was observed in dermatological disorders. While in all the conditions, ANA positivity was high, it was markedly high in chronic liver diseases (CLD) and interstitial lung diseases (ILD), which also showed positivity for certain uncommon patterns ( - Supplementary Table S2, online only).

\section{Discussion}

Autoimmune serology is an important diagnostic tool in a clinical setup in which the ANA is certainly one of the most frequently requested tests in India. ${ }^{7}$ The introduction of human cancer cell lines, Hep-2, as a substrate for the ANA test significantly increased the sensitivity, which however

Table 2 Demographic variables distribution of ANA positivity

\begin{tabular}{|l|l|l|}
\hline $\begin{array}{l}\text { Demographic } \\
\text { variables results }\end{array}$ & $\begin{array}{l}\text { Age } \\
\text { (years) }\end{array}$ & $\begin{array}{l}\text { Gender } \\
\text { (M/F) }\end{array}$ \\
\hline Most positive & $30-39$ & Female \\
\hline Mean (SD) & $37.47(17.78)$ & $73.6 \%$ \\
\hline $\begin{array}{l}\text { Statistical test } \\
\text { applied }\end{array}$ & $\begin{array}{l}\text { t-test-Levene's test } \\
\text { of equality }\end{array}$ & $\begin{array}{l}\text { Chi-square- } \\
\text { Fisher's exact }\end{array}$ \\
\hline Value & 49.852 & 3.777 \\
\hline p-Value & $<0.001$ & 0.03 \\
\hline
\end{tabular}

Abbreviation: ANA, antinuclear antibody; SD, standard deviation. often leads to high-false positive rates, making the interpretation for true positive difficult. This was solved by using a biochip that incorporated primate liver with the Hep-2 cells. The high-sensitivity of Hep-2 cells now needed to be confirmed by the response of the primate liver, which brought the rates of false positives down tremendously. ${ }^{8}$

In a country like India, a laboratory needs adequate, reliable and cheap screening tests. ANA-IIF is not only easy to perform but also cheap. Despite its subjectivity, some of the ANA patterns are specific and are extremely helpful in clinical diagnosis. ${ }^{9}$ With the rise in prevalence of autoimmune disorders in India and scarce documentation of prevalence, any information about their occurrence and clinical significance could be beneficial.

The present study was a patient-based study, and the first study of its kind in central India. ANA test reports of 538 patients were revisited, evaluating the ANA positivity status with the help of IIF on Hep-2 cell lines and primate liver. An ANA positivity rate of $33 \%$ was found. Only two other studies have been undertaken in India, in Bangalore by Sebastian et $\mathrm{al}^{8}$ and in Chandigarh by Minz et al. ${ }^{6}$ Although the frequency of positivity in Bangalore was similar to the present study, Chandigarh showed a lesser positivity (-Table 6). Similar hospital-based studies done in Turkey by Zafer et $\mathrm{al}^{9}$ and Sener et $\mathrm{al}^{10}$ and in Belgium by Peene et $\mathrm{al}^{7}$ had lesser positivity rate compared with present study. Although the results of these studies cannot be considered as prevalence, yet an estimation of disease burden can be made. However, the population-based studies showed mixed results wherein Akmatov et al in Germany ${ }^{4}$ and Chanwit et al in Thailand ${ }^{11}$ found ANA positivity rate to be $33 \%$ and $39.6 \%$, respectively, while Guo et a ${ }^{12}$ in China and Satoh et $\mathrm{al}^{2}$ in the USA demonstrated much lower prevalence. The results contradict the fact that ANA and, in turn, autoimmunity is seen more in Western countries than in India, which could have been a result of previous poor screening facilities. Strikingly, a regional difference is found in India itself, which may be due to climatic variation, genetic variation, and controlling the different molecular mechanisms of autoimmunity, as explained by Atassi et al. ${ }^{13}$ This leaves scope and requirement for further analysis of autoimmunity in the country in different cultures and sects.

Table 3 Age and gender distribution and association in ANA positivity

\begin{tabular}{|l|l|l|l|l|}
\hline Age group (years) & Male (P/T) & Female (P/T) & Exact sig. (2-sided) & Exact sig. (1-sided) \\
\hline $0-9$ & $2 / 17$ & $4 / 12$ & 0.354 & 0.194 \\
\hline $10-19$ & $5 / 23$ & $15 / 39$ & 0.258 & 0.149 \\
\hline $20-29$ & $11 / 31$ & $25 / 70$ & 0.825 & 0.502 \\
\hline $30-39$ & $8 / 32$ & $35 / 91$ & 0.143 & 0.096 \\
\hline $40-49$ & $5 / 23$ & $33 / 81$ & 0.142 & 0.094 \\
\hline $50-59$ & $4 / 23$ & $9 / 48$ & 1.000 & 0.836 \\
\hline $60-69$ & $4 / 10$ & $7 / 16$ & 1.000 & 0.588 \\
\hline $70-79$ & $6 / 10$ & $3 / 8$ & 0.637 & 0.319 \\
\hline$>80$ & $2 / 3$ & $1 / 1$ & 1.000 & 0.750 \\
\hline Total & $47 / 172$ & $132 / 366$ & 0.062 & 0.033 \\
\hline
\end{tabular}

Abbreviation: ANA, antinuclear antibody. 
Table 4 Prevalence of different ANA patterns

\begin{tabular}{|c|c|c|c|c|c|}
\hline Broad pattern & (n) & (\%) & Subtypes of pattern & (n) & $(\%)$ \\
\hline \multirow[t]{8}{*}{ Nuclear } & \multirow[t]{8}{*}{123} & \multirow[t]{8}{*}{68.7} & Nuclear homogenous & 38 & 21.2 \\
\hline & & & Nuclear speckled & 43 & 24.0 \\
\hline & & & Nuclear dotted & 7 & 3.9 \\
\hline & & & Nuclear DFS & 12 & 6.7 \\
\hline & & & Nuclear nucleolar & 16 & 8.9 \\
\hline & & & Nuclear coarse speckled & 4 & 2.2 \\
\hline & & & Nucleus nuclear envelope & 2 & 1.1 \\
\hline & & & Nuclear centromere & 1 & 0.6 \\
\hline \multirow[t]{6}{*}{ Cytoplasmic } & \multirow[t]{6}{*}{34} & \multirow[t]{6}{*}{18.9} & Cytoplasmic AMA & 8 & 4.5 \\
\hline & & & Cytoplasmic speckled & 15 & 8.4 \\
\hline & & & Cytoplasmic fibrillar & 3 & 1.7 \\
\hline & & & Cytoplasmic fibrillar filamentous & 5 & 2.8 \\
\hline & & & Cytoplasmic golgi & 2 & 1.1 \\
\hline & & & Cytoplasmic rods and rings & 1 & 0.6 \\
\hline \multirow[t]{5}{*}{ Mitotic } & \multirow[t]{5}{*}{15} & \multirow[t]{5}{*}{8.4} & Mitotic spindle & 9 & 5.0 \\
\hline & & & Mitotic intercellular bridge & 3 & 1.7 \\
\hline & & & Mitotic centrosome & 1 & 0.6 \\
\hline & & & Mitotic chromosomal & 1 & 0.6 \\
\hline & & & Mitotic NuMa & 1 & 0.6 \\
\hline Mixed & 7 & 3.9 & & 7 & 3.9 \\
\hline Total & 179 & & & 179 & 100 \\
\hline
\end{tabular}

Abbreviations: AMA, antimitochondrial antibodies; ANA, antinuclear antibodies; DFS, dense fine speckled.

Table 5 Disease spectrum in different age groups

\begin{tabular}{|c|c|c|c|c|c|c|c|c|c|c|}
\hline \multirow[t]{2}{*}{ Diagnosis } & \multicolumn{10}{|c|}{ Age groups in years } \\
\hline & $0-9$ & $10-19$ & $20-29$ & $30-39$ & $40-49$ & $50-59$ & $60-69$ & $70-79$ & $>80$ & Total \\
\hline DLE/SLE & 2 & 3 & 1 & 1 & 2 & 1 & 1 & - & - & 11 \\
\hline Rheumatic disorders & 1 & 5 & 1 & 5 & 3 & 2 & - & - & - & 17 \\
\hline Joint pain/swelling & 1 & - & 3 & 3 & 3 & - & 1 & - & - & 11 \\
\hline Skin disorders & - & 2 & 6 & 7 & 4 & 4 & - & - & - & 23 \\
\hline Sclerosis/scleroderma & - & 1 & 1 & 1 & 2 & - & - & - & - & 5 \\
\hline $\begin{array}{l}\text { Hematological } \\
\text { conditions }\end{array}$ & 1 & 5 & 2 & 6 & 3 & 1 & - & - & - & 18 \\
\hline $\begin{array}{l}\text { Infections/ } \\
\text { inflammations }\end{array}$ & 4 & 6 & 3 & 8 & 1 & - & - & - & - & 22 \\
\hline CLD & - & 1 & 1 & 1 & 4 & 2 & 1 & - & - & 10 \\
\hline ILD & - & 1 & 1 & - & 2 & 1 & - & 1 & 1 & 7 \\
\hline Cardiac conditions & - & 2 & 1 & - & 1 & 2 & - & - & - & 6 \\
\hline Nephrotic syndromes & 2 & 2 & - & 0 & 1 & - & - & - & - & 5 \\
\hline $\begin{array}{l}\text { Neuro and musculoskel- } \\
\text { etal conditions }\end{array}$ & - & 1 & 5 & 3 & 3 & 1 & 2 & - & - & 15 \\
\hline Hansen's disease & - & - & - & - & - & 1 & - & - & - & 1 \\
\hline Endocrine conditions & - & - & - & 3 & - & - & - & - & - & 3 \\
\hline Miscellaneous & - & - & 4 & 2 & 1 & - & - & 1 & - & 8 \\
\hline Total & 11 & 29 & 29 & 40 & 30 & 15 & 5 & 2 & 1 & 162 \\
\hline
\end{tabular}

Abbreviations: CLD, cystic lung disease; DLE, discoid lupus erythematosus; ILD, interstitial lung disease; SLE, systemic lupus erythematosus. 
Table 6 Comparing studies done in India and worldwide

\begin{tabular}{|c|c|c|c|c|c|c|c|}
\hline Author & Place of study & Study design & $\begin{array}{l}\text { Sample } \\
\text { size }\end{array}$ & $\begin{array}{l}\text { ANA } \\
\text { prevalence }\end{array}$ & Age & $\begin{array}{l}\text { Male vs } \\
\text { female }\end{array}$ & $\begin{array}{l}\text { Most common ANA } \\
\text { pattern }\end{array}$ \\
\hline Present study & Raipur, India & Patient-based & 536 & $33 \%$ & $37 \pm 18$ & $\begin{array}{l}\text { Female } \\
73.6 \%\end{array}$ & Nuclear speckled \\
\hline $\begin{array}{l}\text { Akmatov } \\
\text { et } \mathrm{al}^{4}\end{array}$ & Germany & Population-based & 1199 & $33 \%$ & $49(38-60)$ & $\begin{array}{l}\text { Female } \\
56.2 \%\end{array}$ & Nuclear Speckled \\
\hline Minz et $\mathrm{al}^{5}$ & $\begin{array}{l}\text { Chandigarh, } \\
\text { India }\end{array}$ & Patient-based & 650 & $18.9 \%$ & $42(20-50)$ & $\begin{array}{l}\text { Female } \\
75.9 \%\end{array}$ & Nuclear speckled \\
\hline Sener et al ${ }^{10}$ & Turkey & Patient-based & 19996 & $21.9 \%$ & - & - & Nuclear homogenous \\
\hline $\begin{array}{l}\text { Sebastian } \\
\text { et al }{ }^{8}\end{array}$ & Bangalore, India & Patient-based & 5066 & $38.2 \%$ & - & - & Nuclear homogenous \\
\hline Zafer et al ${ }^{9}$ & Bolo, Turkey & Patient-based & 3127 & $15.8 \%$ & $43 \pm 18$ & $\begin{array}{l}\text { Female } \\
74.7 \%\end{array}$ & Nuclear speckled \\
\hline $\begin{array}{l}\text { Chanwit } \\
\text { et al }{ }^{11}\end{array}$ & Thailand & Healthy controls & 58 & $39.6 \%$ & $\begin{array}{l}\text { Older age } \\
\text { group }\end{array}$ & Female & Nuclear speckled \\
\hline Guo et al ${ }^{12}$ & China & Population-based & 20970 & $5.9 \%$ & 32 & $\begin{array}{l}\text { Female } \\
72.6 \%\end{array}$ & - \\
\hline Peene et $\mathrm{al}^{7}$ & Belgium & Patient-based & 10550 & $23.5 \%$ & - & - & Nuclear speckled \\
\hline Satoh et $\mathrm{al}^{2}$ & USA & Population-based & 4754 & $13.8 \%$ & $50-59$ & $\begin{array}{l}\text { Female } \\
9.6 \% \text { vs. } \\
17.8 \%\end{array}$ & Nuclear \\
\hline
\end{tabular}

Abbreviations: ANA, antinuclear antibody.

Female predominance in the field of autoimmunity is already established, although the reasons remain obscure. - Table 6 clearly shows that all the studies including the present found ANA positivity rate higher in the female patient or population group. This dominance could be attributed to estrogen as a potential modifier of autoimmunity, as stated by Parks et al. ${ }^{14}$ Hayter et al included microchimerism-induced autoimmunity and action of X-chromosome encoded genes in the reason too. ${ }^{15}$ The female to male ratio, although biased toward the former, varies in proportion in the age groups. The difference peaks in the young adulthood and middle age, tailing at the other ends (-Table $\mathbf{3}$ ). This variation was also pointed out in studies by Guo et al ${ }^{12}$ and Chanwit et al. ${ }^{11}$ This result complemented the result of Parks et al, stating that childbearing may play an important role in initial antigen stimulation or breaking tolerance to self-antigens contributing to the development of ANA..$^{14}$

According to Beeson, as stated in his compilation, ${ }^{16}$ the events of the autoimmune disorders are high in the 20 to 50 age group, while Hayter et al pin pointed the 20 to 29 age group with the highest prevalence of autoimmune disorders. ${ }^{15}$ This corresponds to the higher prevalence of autoimmune disorders ( - Table 5 ) and of ANA positivity (-Supplementary Table S1, online only) in this group, as seen in present study, with the mean age being $37 \pm 18$ years. This result was similar to that of Guo et al in China (mean age 32 years). ${ }^{12} \mathrm{~A}$ higher mean age was reported by Akmatov et al, Minz et al and Zafer et al ( 49 years, 42 years and 43 years, respectively), ${ }^{4,69}$ while Satoh et al and Chanwit et al found the highest prevalence in the older age group.,11 This difference could be accounted to study population composition. The ANA in older people could suggest a senile condition rather than a pathological problem. Despite this age distribution, certain conditions occur more in certain age groups like infections and rheumatic disorders in teenagers, neurological manifestations in old age while ILD in low rate appear equally in all age groups.

The nuclear pattern as a whole is unquestionably the most common in all the studies worldwide. Among this, the nuclear homogenous and nuclear speckled patterns come to the forefront. The nuclear speckled pattern is almost evenly distributed in all age groups except the pediatric group which also does not show nuclear homogenous pattern positivity just like Chanwit et al in Thailand. ${ }^{11}$ The result of present study was similar to study done by Minz et al in Chandigarh and Zafer et al in Turkey, showing high-ANA positivity in SLE and DLE, scleroderma and rheumatoid patients. ${ }^{6,9}$ However, the most common pattern associated with SLE was nuclear homogenous in contrast to nuclear speckled in their studies. Minz et al in their article on review of diagnostics in autoimmunity stated that SLE showed positivity for both nuclear homogenous and nuclear speckled. ${ }^{5}$ This was in agreement to Hayter et al who pointed to the possibility of multiple tissue and molecular targets in SLE. ${ }^{15}$ It is often thought that the uncommon patterns have no role to play in diagnosis. However, the present study and studies done by Chanwit et al and Sener et al found the rare ANA patterns in significant number, and also disease conditions associated with them, especially chronic hepatic conditions and carcinoma. ${ }^{10,11}$ This supported the extensive study done by Pieter et al on rare ANA patterns, and his conclusion of nuclear envelope and nuclear dot patterns was associated with autoimmune hepatitis and hepatic and colon carcinoma. ${ }^{17}$ The cytoplasmic patterns are also considered nondisease-specific but their significance should not be ignored, as stated by Chanwit et al, since they might as well point to certain undetected conditions. ${ }^{11}$ 
This study has certain limitations in terms of adequate clinical data available, lack of reference in neighborhood, and the study design being retrospective. However, its strength lies in the fact that it is the first of its kind in central India, providing an overview of ANA and autoimmunity status in this region..

\section{Conclusion}

Young age with dermatological manifestation in SLE was the commonest presentation. Although nuclear speckled was the most frequent pattern, few unusual patterns were also observed. A prospective study is needed to understand not only the epidemiology of autoimmune disorders but also the predictive value of ANA IIF in clinical setup, besides considering the possibility of taking up IIF as a screening tool for autoimmune disorders.

\section{Ethical Approval}

Approval taken from Institute Ethics Committee, AIIMS Raipur (745/IEC-AIIMSRPR/2019).

\section{Guarantor}

RN.

\section{Contributorship}

PG was involved in gaining ethical approval, performed data analysis, and wrote the first draft of the manuscript; RP conducted research work on literature, protocol development, and sample analysis; RN conceived the study, performed data analysis, and reviewed the manuscript; SP and EM reviewed and edited the manuscript. All authors approved the final version of the manuscript.

\section{Conflict of Interest}

None declared.

\section{References}

1 Elena M, Hernández-becerril N, Perez-chiney AC, et al. Results in Immunology Predictive value of antinuclear antibodies in autoimmune diseases classified by clinical criteria: analytical study in a specialized health institute, one year follow-up. Results Immunol 2015;5:13-22
2 Satoh M, Chan EKL, Ho LA, Rose M, Parks CG, Cohn RD, et al. Study design. 2013;64(7):2319:27

3 Gautam K. Anti-Nuclear antibodies: current concepts and future direction for diagnosing connective tissue disease. Journal of Pathology of Nepal 2015;5:766-773

4 Akmatov MK, Röber N, Ahrens W, et al. Anti-nuclear autoantibodies in the general German population: prevalence and lack of association with selected cardiovascular and metabolic disorders-findings of a multicenter population-based study. Arthritis Res Ther 2017;19(1):127

5 Kumar Y, Bhatia A, Minz RW. Antinuclear antibodies and their detection methods in diagnosis of connective tissue diseases: a journey revisited. Diagn Pathol 2009;4:1

6 Minz RW, Kumar Y, Anand S, et al. Antinuclear antibody positive autoimmune disorders in North India: an appraisal. Rheumatol Int 2012;32(9):2883-2888

7 Peene I, Meheus L, Veys EM. De Keyser F. Detection and identification of antinuclear antibodies (ANA) in a large and consecutive cohort of serum samples referred for ANA testing. Ann Rheum Dis 2001;60(12):1131-1136

8 Sebastian W, Roy A, Kini U, Mullick S. Correlation of antinuclear antibody immunofluorescence patterns with immune profile using line immunoassay in the Indian scenario. Indian J Pathol Microbiol 2010;53(3):427-432

9 Mengeloglu Z, Tas T, Kocoglu E, Aktas G, Karabörk S. Determination of anti-nuclear antibody pattern distribution and clinical relationship. Pak J Med Sci 2014;30(2):380-383

$10 \mathrm{Ag} \mathrm{S}$, Afsar I. Evaluation of antinuclear antibodies by indirect immunofluorescence and line immunoassay methods 0 : four years 0 data from Turkey. APMIS 2014;122(12):1167-1170

11 Prapinjumrune C, Prucktrakul C, Sooktonglarng T, Thongprasom K. Serum antinuclear antibody in adult Thais. Gerodontology 2017;34(1):86-89

12 Guo YP, Wang CG, Liu X, et al. The prevalence of antinuclear antibodies in the general population of china: a cross-sectional study. Curr Ther Res Clin Exp 2014;76:116-119

13 Atassi MZ, Casali P. Molecular mechanisms of autoimmunity. Autoimmunity 2008;41(2):123-132

14 Birnbaum LS, Jusko TA, Kissling GE, et al. HHS public access. J Immigr Minor Health 2015; (919):1-21

15 Hayter SM, Cook MC. Autoimmunity reviews updated assessment of the prevalence, spectrum and case definition of autoimmune disease. Autoimmun Rev 2012;11(10):754-765

16 Beeson PB. Age and sex associations of 40 autoimmune diseases. Am J Med 1994;96(5):457-462

17 Vermeersch P, Bossuyt X. Autoimmunity reviews prevalence and clinical significance of rare antinuclear antibody patterns. Autoimmun Rev 2013;12(10):998-1003 